\title{
Proposição de modelos de geração de viagens para Belo Horizonte
}

\author{
Leise Kelli de Oliveira ${ }^{1}$, Luciana Carneiro de Morais Stubbs ${ }^{2}$, Nebai Tavares Gontijoº \\ Renata Lúcia Magalhães de Oliveira ${ }^{3}$ \\ 1Universidade Federal de Minas Gerais, leise@etg.ufmg.br \\ 2Empresa de Transporte e Trânsito de Belo Horizonte, lucic@pbh.gov.br; nebai@pbh.gov.br \\ ${ }^{3}$ Centro Federal de Educação Tecnológica de Minas Gerais, renataoliveira@cefetmg.br
}

\section{Recebido:}

01 de setembro de 2016

Aceito para publicação:

21 de junho de 2017

Publicado:

31 de agosto de 2017

Editor de área:

Helena Beatriz Cybis, UFRGS

\section{Palavras-chaves:}

Modelos de geração de viagens.

Polos geradores de viagens.

Belo Horizonte.

\section{Keywords:}

Trip generation models.

Trip generation poles.

Belo Horizonte.

DOI:10.14295/transportes.v25i2.1243

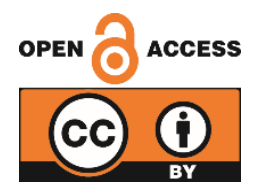

\begin{abstract}
RESUMO
Este artigo apresenta modelos de geração de viagens para sete categorias de empreendimentos (casas noturnas, condomínios residenciais, escolas de ensino fundamental e médio, hospitais, instituições de ensino superior, shopping centers e supermercados) para Belo Horizonte. Contagem classificada volumétrica de veículos, entrevistas e dados de controle de acesso foram utilizados para identificar as características dos empreendimentos e desenvolver os modelos. Os modelos desenvolvidos apresentaram boa correlação entre as variáveis utilizadas e significância estatística, exceto para condomínios residenciais e supermercados. A validação dos modelos indicou uma boa aproximação com os dados coletados em campo. A comparação com os modelos da literatura nacional indicou que investigar e desenvolver estudos para uma cidade é importante quando há necessidade de utilizá-los em estudos de impacto viário para determinação de medidas mitigadoras na implantação dos empreendimentos de impacto. Desta forma, os modelos locais são mais precisos e tendem a produzir menores erros na projeção, permitindo uma avaliação mais confiável e adequada das medidas mitigadoras necessárias para o empreendimento.
\end{abstract}

\begin{abstract}
This paper presents trip generation models for Belo Horizonte, considering seven categories of enterprises (nightclubs, residential condominiums, elementary and high schools, hospitals, higher education institutions, shopping centers, and supermarkets). Counting and classification of traffic volume, interviews and access control data were used to identify characteristics of each type of enterprise and to develop the models. A good fit among the variables collected was achieved, except to the categories residential condominiums, and supermarkets. The models show a strong correlation among the variables considered, besides their statistical significance. A comparative analysis of models from the Brazilian literature indicated that the development of such

models are important for urban areas to assess traffic impact and to determine mitigation strategies due to the implementation of large enterprises. Local models are more precise and have the tendency to produce smaller errors in estimates, permitting a more reliable and accurate evaluation of the mitigation strategies that should be implemented.
\end{abstract}

\section{INTRODUÇÃO}

São notórios os impactos relacionados aos grandes empreendimentos urbanos na infraestrutura de transporte. Os primeiros estudos relacionados a tais empreendimentos, inicialmente denominados pelos geradores de tráfego, procuravam avaliar os impactos no tráfego decorren- 
tes do funcionamento do empreendimento. Porém, tais impactos tomaram dimensões mais amplas, e hoje chegam a contribuir com a alteração da própria estrutura espacial das cidades (Gonçalves et al., 2012).

Em geral, empreendimentos que geram um grande número de viagens são denominados de polos geradores de viagens (PGV). 0 Código de Trânsito Brasileiro (Brasil, 2009) denomina tais empreendimentos como polos atrativos de trânsito, destacando a necessidade de sua aprovação por órgão competente.

Existe um consenso quanto à definição dos PGVs apresentada por Grando (1986), pela Companhia de Engenharia de Tráfego de São Paulo (CET-SP, 1983) e pelo Departamento Nacional de Trânsito (Denatran, 2001). De forma unívoca, os PGVs são definidos como empreendimentos que, mediante a oferta de bens e/ou serviços, produzem e/ou atraem um grande número de viagens, causando reflexos na circulação de tráfego no seu entorno, tanto em termos de acessibilidade e fluidez do tráfego, podendo repercutir em toda uma região, quanto em termos da segurança de veículos e pedestres.

Com um conceito mais amplo, Portugal e Goldner (2003) definem PGVs como locais ou instalações, de distintas naturezas, que desenvolvem atividades de porte e escala capazes de produzir um contingente significativo de viagens.

Os grandes empreendimentos e construções classificados como PGVs podem gerar impactos negativos e positivos no meio em que eles estão instalados, alterando, dessa forma, a qualidade de vida da população que habita ou transita pelo local em questão. Tais impactos podem estar direta ou indiretamente relacionados a eles, por serem consequência do tráfego que eles geram (Gonçalves et al., 2012). Os impactos diretos estão relacionados ao sistema viário e à circulação, implicando no aumento de veículos, tempo de viagem, conflitos no tráfego, estacionamento e acidentes. Os impactos indiretos derivam da alteração do ambiente urbano, redução da mobilidade e acessibilidade, além de impactos econômicos e ambientais (Kneib, 2004).

Neste contexto, este artigo apresenta uma revisão dos modelos nacionais de polos geradores de viagens para sete diferentes categorias de empreendimentos (casas noturnas, condomínios residenciais, escolas de ensino fundamental e médio, hospitais, instituições de ensino superior, shopping centers e supermercados), visando subsidiar o desenvolvimento dos modelos locais. 0 objetivo central deste trabalho é gerar modelos locais para cada um dos segmentos apresentados para Belo Horizonte. Justifica-se a escolha desta cidade devido ao fato de que, no período entre 1998 e 2016, 1.036 estabelecimentos foram licenciados nesse município por meio da análise do tráfego, sendo que 31,27\% correspondem às categorias estudadas neste trabalho.

Ainda, os modelos desenvolvidos neste estudo serão comparados com a literatura para confirmar a afirmação de Grieco e Portugal (2010) quanto à necessidade de modelos compatíveis com as particularidades locais. Assim, a principal contribuição deste estudo é apresentar modelos de geração de viagens locais, com o objetivo de contribuir para o planejamento urbano e operacional de transportes para a cidade de Belo Horizonte. Com isso, fortalece-se a afirmativa de que os modelos compatíveis com as particularidades locais são fundamentais para a análise do impacto de grandes empreendimentos no sistema de transporte.

\section{MODELOS DE GERAÇÃO DE VIAGENS}

A literatura ibérico-americana sobre modelos de polos geradores de viagens está detalhadamente apresentada em Portugal (2012). Assim, nesta seção, é apresentada uma descrição geral das abordagens adotadas para as categorias de empreendimentos discutidas neste artigo, in- 
cluindo os estudos que serão usados para comparação com os modelos aqui apresentados. Para maiores detalhes sobre os modelos, sugere-se consultar Portugal (2012).

Na Tabela 1 são apresentados os principais modelos nacionais abordados nesta seção de revisão de literatura. É importante apresentar tais modelos para, posteriormente, comparar com os resultados obtidos Belo Horizonte. Ressalta-se que a apresentação dos modelos publicados na Tabela 1 apresenta algumas lacunas. Isto se deve às diferentes naturezas metodológicas e às diferentes apresentações de resultados presentes na literatura. As informações não apresentadas nesta tabela são consistentes com as lacunas de explanações encontradas nos respectivos estudos publicados.

Tabela 1: Modelos de geração de viagens no contexto brasileiros para as categorias de empreendimentos objeto de estudo deste artigo

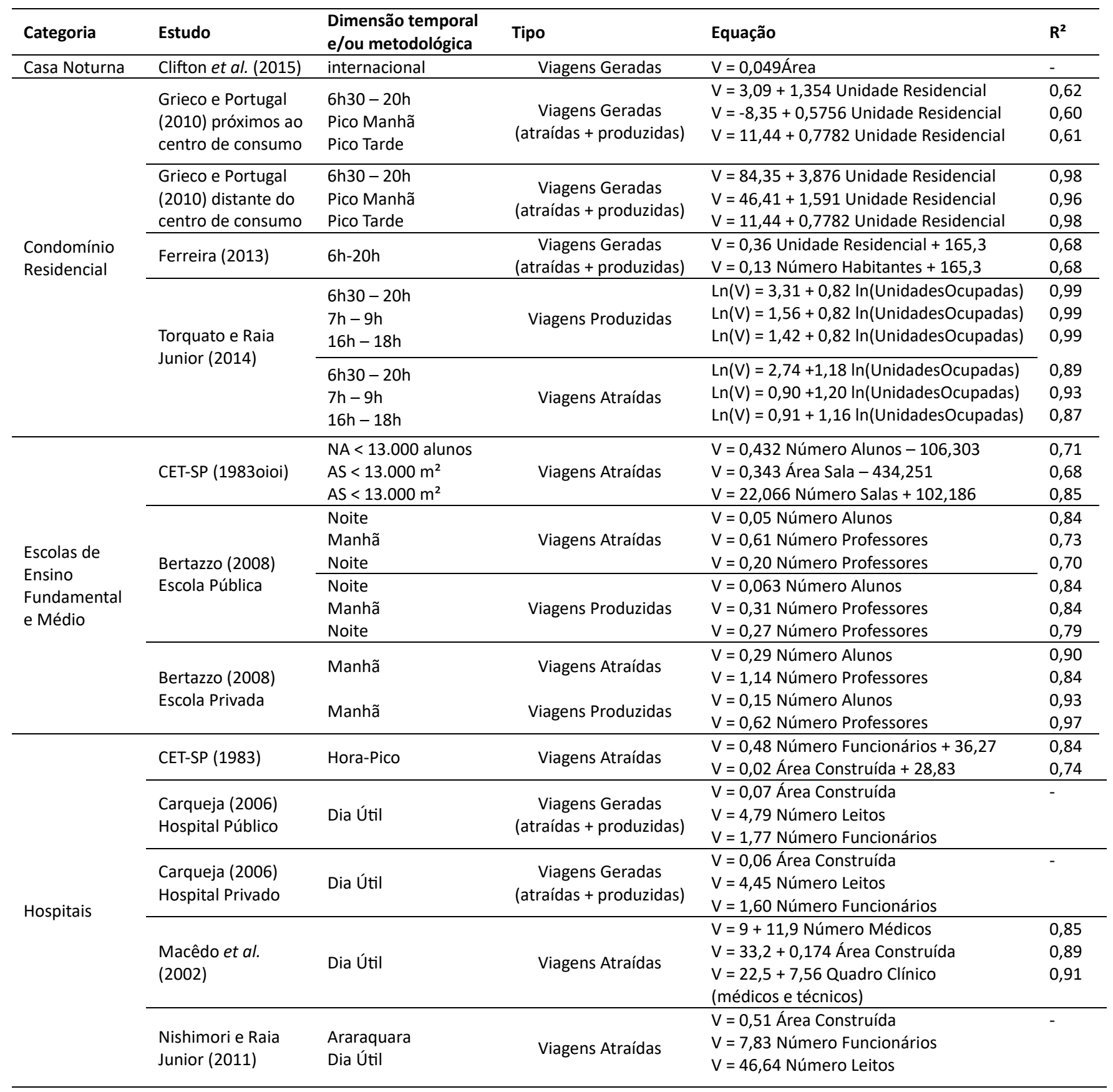


Tabela 1: Modelos de geração de viagens no contexto brasileiros para as categorias de empreendimentos objeto de estudo deste artigo (continuação)

\begin{tabular}{|c|c|c|c|c|c|}
\hline Categoria & Estudo & $\begin{array}{l}\text { Dimensão temporal } \\
\text { e/ou metodológica }\end{array}$ & Tipo & Equação & $\mathbf{R}^{2}$ \\
\hline \multirow{3}{*}{ Hospitais } & \multirow{3}{*}{ Gontijo (2014) } & \multirow{3}{*}{ Dia Útil } & \multirow{3}{*}{ Viagens Atraídas } & $V=2005,85+0,1$ AreaConstruída & 0,67 \\
\hline & & & & $\begin{array}{l}V=1373,41+3,43 \\
\text { NúmeroFuncionários }\end{array}$ & 0,88 \\
\hline & & & & $\mathrm{V}=1899,30+8,93$ NúmeroLeitos & 0,84 \\
\hline \multirow{4}{*}{ IES } & TECTRAN (2003a) & Dia e Hora-Pico & $\begin{array}{l}\text { Viagens Geradas } \\
\text { (atraídas + produzidas) }\end{array}$ & $\begin{array}{l}\mathrm{V}=1,710 \text { NúmeroÚsuários } \\
V_{\text {atraídas_pico }}=0,213 \mathrm{~V} \\
V_{\text {produzidas_pico }}=0,046 \mathrm{~V}\end{array}$ & - \\
\hline & TECTRAN (2003b) & Hora-Pico & Viagens Atraídas & $\begin{array}{l}V=1,174 \times \text { NúmeroAlunos } \times \text { Fator Hora } \\
\text { Pico }\end{array}$ & - \\
\hline & \multirow{2}{*}{ Souza (2007) } & Início do Turno & Viagens Atraídas & $V_{\text {alunos }}=0,53$ NúmeroAlunos & 0,94 \\
\hline & & Término do Turno & Viagens Produzidas & $\mathrm{V}_{\text {alunos }}=0,49$ NúmeroAlunos & 0,93 \\
\hline \multirow{6}{*}{$\begin{array}{l}\text { Shopping } \\
\text { Center }\end{array}$} & CET-SP (1983) & Hora Pico & Viagens Atraídas & $V=0,25(0,124$ ÁreaBruta +1.550$)$ & - \\
\hline & $\begin{array}{l}\text { CET-SP (2000) } \\
\text { Amostra }=7\end{array}$ & $\begin{array}{l}\text { Sexta-feira } \\
\text { Sábado }\end{array}$ & Viagens Atraídas & $\begin{array}{l}V=0,28 \text { ÁreaConstruída }-1.366,12 \\
V=0,33 \text { ÁreaConstruída }-2.347,55\end{array}$ & $\begin{array}{l}0,99 \\
0,99\end{array}$ \\
\hline & Cádenas (2003) & Sábado & Viagens Atraídas & $V=0,27$ ÁreaBrutaLocável $+1.190,42$ & $\begin{array}{l}0,91 \\
0,86\end{array}$ \\
\hline & Goldner (1994) & Sábado & Viagens Atraídas & V = 0,31 ÁreaBrutaLocável + 1.732,7 & 0,89 \\
\hline & \multirow{2}{*}{$\begin{array}{l}\text { Jacobsen et al. } \\
(2010)\end{array}$} & Sexta-feira & \multirow{2}{*}{ Viagens Atraídas } & $V=-7,62+0,26$ ÁreaBrutaLocável & 0,75 \\
\hline & & Sábado & & $V=-11,41+0,33$ ÁreaBrutaLocável & 0,70 \\
\hline \multirow{6}{*}{$\begin{array}{l}\text { Supermerca- } \\
\text { dos }\end{array}$} & CET-SP (1983) & Hora-pico & Viagens Atraídas & $V=(0,4 A C o+600)$ FatorHoraPico & - \\
\hline & $\begin{array}{l}\text { Barbosa e } \\
\text { Gonçalves (2000) }\end{array}$ & Dia-pico & Viagens Atraídas & $\mathrm{V}=383+0,32$ ÁreaVendas + 907Lojas & 0,97 \\
\hline & \multirow{4}{*}{ Freitas (2009) } & \multirow{4}{*}{ Hora-pico } & \multirow{4}{*}{ Viagens Atraídas } & V = 0,031 ÁreaConstruída - 48 & 0,90 \\
\hline & & & & V = 0,023 ÁreaConstruída + & 0,95 \\
\hline & & & & $1,37\left(\mathrm{hab} / \mathrm{m}^{2}\right)-49,3$ & \\
\hline & & & & $\begin{array}{l}V=0,02 \text { ÁreaConstruída }+0,84 \\
\text { NúmeroVagas }-76,5\end{array}$ & 0,95 \\
\hline
\end{tabular}

\subsection{Casas Noturnas}

Apesar da real necessidade da análise do impacto do fluxo gerado por esta categoria de empreendimento no sistema viário, não foram encontrados, na literatura, modelos de geração de viagens específicos para casas noturnas. Nacionalmente, devido à similaridade em relação às características do empreendimento, recomenda-se a leitura do trabalho de Pinto et al. (2012), que apresenta a análise dos impactos de megaeventos no sistema de transporte. Em nível internacional, dois estudos são apresentados, a saber: (i) ITE (2008), que discutem taxas para estabelecimentos comerciais sob o código "locais para beber" (ITE land use 925 - drinking places); e (ii) Clifton et al. (2015), que estimaram modelos para esta categoria de estabelecimentos que foram ajustados e comparados às taxas do ITE.

\subsection{Condomínios Residenciais}

O estudo da geração de viagens em empreendimentos residenciais é de fundamental importância (Grieco et al., 2012), visto que é um empreendimento comum em aglomerações urbanas. No Brasil, o estudo da geração de viagens em residências é ainda pouco explorado, segundo Grieco e Portugal (2010), mas necessário para se dispor de taxas e modelos mais compatíveis com a realidade. Em geral, os modelos utilizam como variáveis, o número de unidades residenciais (Marcolini, 2011), unidades ocupadas (Castro, 2010; Marcolini, 2011; Torquato e Raia Junior, 2014), vagas de estacionamento (Marcolini, 2011) e a área total do empreendimento (Castro, 2010; Torquato e Raia Junior, 2014). Ainda, os dados foram obtidos por contagem volumétrica classificada (Marcolini, 2011; Torquato e Raia Junior, 2014), entrevistas (Marcolini, 2011) e dados secundários (Marcolini, 2011). 


\subsection{Escolas de Ensino Fundamental e Médio}

Segundo Bertazzo et al. (2014), não obstante a importância de estudos das instituições de ensino como PGVs, a produção científica referente à geração de viagens para esses empreendimentos ainda é escassa, tanto em termos de variáveis independentes e períodos analisados, como pelo pequeno número de estudos.

As viagens geradas por instituições de ensino ocorrem de modo regular e previamente programado, especialmente nos dias úteis, e os picos de geração de viagens coincidem com os picos de tráfego do sistema viário (Bertazzo et al., 2012). Em estabelecimentos de ensino, as características das viagens dependem de variáveis como: o tipo de ensino ofertado, categoria da instituição (pública ou privada), localização (urbana, suburbana, rural), acesso ao sistema de transporte e disponibilidade de infraestrutura, como vagas de estacionamento e área para operação de embarque e desembarque (Bertazzo et al., 2012).

A CET-SP (1983) utiliza o número total de alunos, a área total de salas de aula $\left(\mathrm{m}^{2}\right)$ e o número de salas de aula como variáveis para os modelos de geração de viagens. Mais recentemente, CET-SP (2000) apresentou modelos para escolas de ensino fundamental e médio, divididas em quatro grupos conforme os níveis de ensino ofertados: (i) ensino pré-escolar, fundamental e médio; (ii) ensino fundamental e pré-escolar; (iii) ensino fundamental e médio; (iv) ensino fundamental.

\subsection{Hospitais}

Os empreendimentos de saúde podem ser classificados como postos de saúde, centros de saúde, policlínicas, hospitais gerais, hospitais especializados, prontos-socorros gerais, prontos-socorros especializados, consultórios e clínicas especializadas ou ambulatórios de especialidade. Estes empreendimentos podem ser públicos, públicos universitários ou privados.

Os principais estudos sobre a geração de viagens em hospitais são CET-SP (1983), Carqueja (2006), Macêdo et al. (2002), Nishimori e Raia Junior (2011), Gontijo (2014). CET-SP (1983) utiliza a área construída e o número de funcionários como variáveis para o modelo de geração de viagens. Macêdo et al. (2002) estimaram as viagens geradas por clínicas em Goiânia (GO), para, posteriormente, estimar a quantidade de vagas de estacionamento. Este estudo considerou como variáveis independentes o número de médicos, consultórios, área total construída, especialidades médicas e número de convênios. Nishimori e Raia Junior (2011) desenvolveram um estudo de geração de viagens para prontos-socorros, com dados de duas cidades de porte médio, Araraquara e Jaú, localizadas no interior de São Paulo. Gontijo (2014) apresentou taxas e modelos que permitem analisar os possíveis impactos em relação às viagens atraídas por novos empreendimentos hospitalares, por meio de dados do Estado de São Paulo.

\subsection{Instituições de Ensino Superior}

TECTRAN (2003a, 2003b) apresentaram taxas de geração de viagens, utilizando fatores de hora-pico para estimar as viagens atraídas e produzidas pelas Instituições de Ensino Superior (IESs). Os modelos utilizam o número de usuários como variável explicativa e as viagens geradas são transformadas em viagens por modo de transporte, de acordo com a distribuição modal do estabelecimento analisado. Nunes (2005) apresentou parâmetros para a estimativa do número de vagas de estacionamento para instituições de ensino superior (IES) localizadas no Distrito Federal (DF), utilizando o número de alunos como variável explicativa para determinar a demanda crítica (número de vagas de estacionamento a ser oferecido pela IES). Souza (2007), 
por sua vez, determinou taxas e modelos de geração de viagens para os principais modos de transporte utilizados para acesso às IES do Distrito Federal.

\subsection{Shopping Centers}

Para Andrade e Portugal (2012b), os shopping centers são comumente contemplados nos estudos de impacto de vizinhança e geração de viagens pela sua capacidade de gerar viagens. Podem ser caracterizados como polos geradores de viagens que integram estabelecimentos comerciais e de prestação de serviços em uma única estrutura (Jacobsen et al., 2010).

0 modelo da CET-SP (2000) foi elaborado para a estimativa de viagens desta categoria de estabelecimento no município de São Paulo e é amplamente difundido. Como exemplo, o manual de PGT do DENATRAN (2001) recomenda a utilização dos modelos da CET-SP (2000) e Goldner (1994) para geração de viagens em shopping centers. Alguns dos modelos encontrados na literatura são CET-SP (1983), Cádenas (2003), Goldner (1994), Rosa (2003) e Jacobsen et al. (2010). As principais variáveis consideradas nos estudos presentes na literatura são: área, área bruta locável, tipo (com ou sem supermercado), área computável (área construída subtraída das áreas de garagens, áticos e caixas d'água) e renda média mensal (CET-SP, 1983; Goldner, 1994; Rosa, 2003, CET-SP, 2000; CET-SP, 2011).

\subsection{Supermercados}

Para Galarraga et al. (2012), os critérios recomendados para estudos e análises de PGVs, tais como supermercados, são o padrão (tipo e porte do estabelecimento), dimensão temporal e metodológica. Existem outros trabalhos na literatura que versam sobre os supermercados como polo gerador de viagem, podendo-se destacar alguns: (i) modelos de geração de viagens (CETSP, 2000; Barbosa e Gonçalves, 2000); (ii) divisão modal e modelo de geração de viagens (Portugal e Goldner, 2003) e, (iii) metodologia para determinação de área de influência e modelo de geração de viagem (Silva, 2006). Todos eles estudaram cidades com mais de 500.000 habitantes. Silva et al. (1995) pesquisaram vagas de estacionamento em supermercados na cidade de São Carlos (SP). No contexto de Belo Horizonte, Barbosa e Gonçalves (2000) analisaram dez supermercados, com dados obtidos junto à Associação Mineira de Supermercados (AMIS).

\section{METODOLOGIA}

Dentre as metodologias disponíveis para estimativa das viagens geradas por PGV, utilizou-se, neste estudo, a abordagem metodológica proposta pelo Institute of Transportation Engineering (ITE, 2008), que também tem sido utilizada em outras pesquisas acadêmicas nos países iberoamericanos.

Segundo Andrade e Portugal (2012a), no desenvolvimento dos modelos, deve-se incorporar, na dimensão metodológica, a abordagem e a forma de obtenção de dados, as variáveis explicativas, os elementos da amostra e a data da pesquisa. Para o desenvolvimento da pesquisa, considerou-se a abordagem e a apresentação dos resultados considerando recomendação de ITE (2008) e Andrade e Portugal (2012a), a saber:

- considerar a natureza do modelo proposto;

- hora de projeto: recomenda-se que o foco seja dado aos dias e horários de maior carregamento do tráfego externo e do pico do empreendimento;

- escolher PGVs existentes que reúnam características similares às que se pretende modelar 
para a demanda de viagens. Deve-se verificar se o PGV está em plena concordância em relação ao porte, tipo e localização com o escopo da pesquisa. É importante que o PGV esteja consolidado, ou seja, em pleno funcionamento há algum tempo. Com pelo menos três empreendimentos, é possível se chegar a uma taxa média de geração de viagens. Com cinco empreendimentos, é possível utilizar equações de regressão linear, mas o desejável é ter pelo menos 20 elementos na amostra;

- seleção de variável independente: a variável independente é a grandeza que explicará estatisticamente o volume de viagens geradas por um PGV. ITE (2008) recomenda para escolha da variável explicativa: (i) motivo da variação da quantidade de viagens produzidas por uso do solo; (ii) ser obtida por medição primária; (iii) produzir taxa ou equação com os melhores índices de acerto; (iv) ser de fácil acesso; (iv) ser relacionada à construção;

- coletar dados sobre cada PGV: os dados podem ser obtidos através de contagens in loco, por meio de questionários enviados a administradores e com questionários destinados aos usuários do PGV;

- verificar a correlação estatística entre o volume de viagens e as variáveis independentes;

- desenvolver os modelos, utilizando regressão linear como abordagem metodológica. A avaliação da acurácia do modelo será realizada considerando o coeficiente de explicação $\left(\mathrm{R}^{2}\right)$ e o teste-t;

- validar o modelo

a abordagem considerada para validação dos modelos foi leave-one-out cross-validation (LOOCV). Neste método, uma única observação $\left(x_{1}, y_{1}\right)$ é utilizada como conjunto de validação e as observações restantes $\left\{\left(x_{2}, y_{2}\right), \ldots,\left(x_{n}, y_{n}\right)\right\}$ compõem o conjunto de treinamento. 0 método de aprendizagem estatística é ajustado ao conjunto de treinamento $n-1$ e o valor estimado $\hat{y}_{1}$ é gerado para a observação excluída, considerando o valor da variável independente $x_{1}$. Uma vez que $\left(x_{1}, y_{1}\right)$ não foi utilizado no processo de ajuste do modelo, o erro quadrático $E Q_{1}=\left(y_{1}-\hat{y}_{1}\right)^{2}$ fornece uma estimativa pouco tendenciosa para o teste de erro. Esse processo é repetido, tomando conjunto de validação $\left(x_{2}, y_{2}\right)$, treinando as $n-1$ observações $\left\{\left(x_{1}, y_{1}\right),\left(x_{3}, y_{3}\right), \ldots,\left(x_{n}, y_{n}\right)\right\}$ por meio do procedimento de aprendizagem estatística e calculando o $E Q M_{2}=\left(y_{2}-\hat{y}_{2}\right)^{2}$. Este processo é repetido $n$ vezes, produzindo $n$ erros quadráticos $E Q_{1}, \ldots, E Q_{n}$. A estimativa erro quadrático médio (EQM) para o teste dos erros quadráticos médios é a média destas $n$ estimativas de erros (Equação 1).

$$
E Q M=\frac{1}{n} \sum_{i=1}^{n} E Q_{i}
$$

A abordagem LOOCV apresenta duas principais vantagens sobre a validação considerando sub-conjuntos dos dados observados. Primeiramente, apresenta menos viés. Na LOOCV, o método de aprendizagem estatística é ajustado repetidamente utilizando os conjuntos de treinamento (contendo $n-1$ observações), praticamente o número de observações. Consequentemente, a abordagem LOOCV tende a não superestimar o teste de erro. Segundo, em contraste com a abordagem de validação que permite diferentes resultados quando aplicada repetidamente devido à aleatoriedade das partições de conjuntos de treinamento e validação, o LOOCV não apresenta aleatoriedade na repartição destes conjuntos. 
A partir da determinação do EQM, realizou-se o cálculo da raiz quadrada deste erro, resultando na raiz quadrada do erro quadrático médio (REQM). Este último indicador foi comprado para os modelos com diferentes variáveis explicativas e o melhor desempenho foi identificado para o modelo com menor REQM. Este processo foi realizado para cada categoria de dados.

- caso os modelos desenvolvidos não sejam validados, deve-se retornar à etapa de coleta de dados para obtenção de uma amostra com maior acurácia.

\section{CARACTERIZAÇÃO DA ÁREA DE ESTUDO}

Este estudo foi desenvolvido para Belo Horizonte, um dos principais centros urbanos brasileiros, com uma população estimada de 2,5 milhões de habitantes, distribuídos por $331 \mathrm{~km}^{2} \mathrm{e}$ densidade demográfica de 7.167 hab./ $\mathrm{km}^{2}$. Belo Horizonte responde por $14,5 \%$ do Produto Interno Bruto (PIB) de Minas Gerais e 1,33\% do PIB do Brasil e ocupa, dessa forma, a quinta posição no ranking dos municípios brasileiros, segundo o valor do PIB Municipal (Figura 1).

A Prefeitura de Belo Horizonte define empreendimentos de impacto como aqueles, públicos ou privados, que venham sobrecarregar a infraestrutura urbana ou ter repercussão ambiental significativa. Além disso, segundo Belo Horizonte (2010), os empreendimentos de impacto ficam sujeitos ao licenciamento ambiental ou licenciamento urbanístico, de acordo com os respectivos impactos. São passíveis de licenciamento ambiental os empreendimentos, dentre outros, terminais rodoviários, ferroviários e aeroviários, garagem de empresas de transporte de passageiros e de cargas, loteamentos e hospitais. São passíveis de licenciamento urbanístico os seguintes empreendimentos de impacto (Belo Horizonte, 2010):

- edifícios não residenciais com área de estacionamento maior que $10.000 \mathrm{~m}^{2}$ ou com mais de 400 vagas de estacionamento;

- edifícios destinados ao uso residencial que tenham mais de 300 unidades;

- edifícios destinados ao uso misto com mais de $20.000 \mathrm{~m}^{2}$;

- edifícios destinados a serviço de uso coletivo com área maior que $6.000 \mathrm{~m}^{2}$;

- casas de show, independentemente da área utilizada;

- centro de convenções, independentemente da área utilizada;

- casa de festas e eventos com área utilizada superior a $360 \mathrm{~m}^{2}$;

- hipermercados com área utilizada igual ou superior a $5.000 \mathrm{~m}^{2}$;

- parcelamentos vinculados, provenientes de desmembramento, que originem lote com área superior a $10.000 \mathrm{~m}^{2}$ ou quarteirão com dimensão superior a 200 metros;

- intervenções em áreas urbanas consolidadas, compreendidas por modificações geométricas significativas de conjunto de vias de tráfego de veículos;

helipontos;

- outros empreendimentos sujeitos a estudo de impacto de vizinhança (EIV) definidos por lei municipal.

Os empreendimentos listados acima estão sujeitos a estudo de impacto viário. 0 estudo para fins de licenciamento, realizado para empreendimentos de impacto, deverá prever a revisão e a adequação do zoneamento da área impactada pela intervenção. 


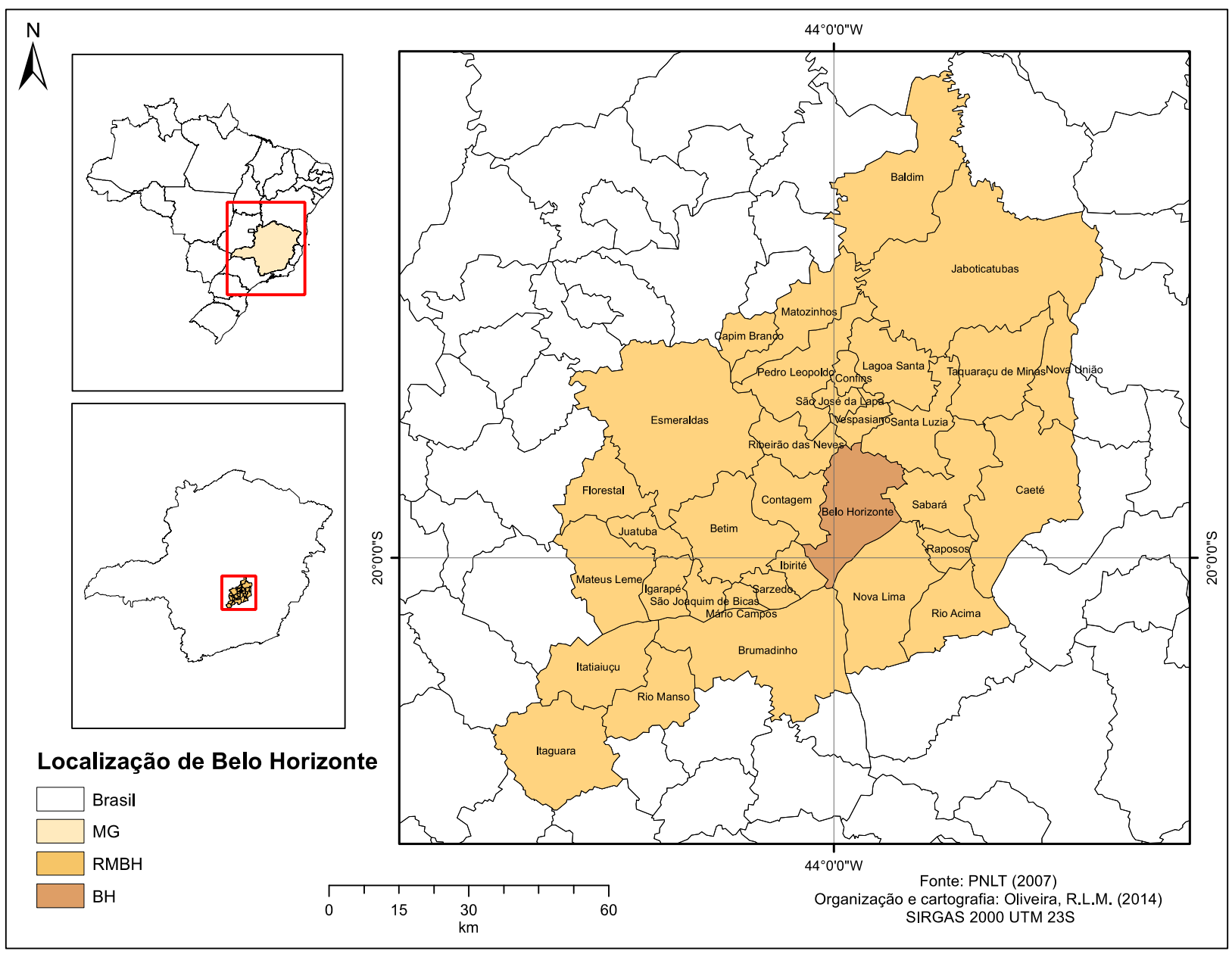

Figura 1. Mapa de Localização do município de Belo Horizonte

\subsection{Obtenção de dados e caracterização dos empreendimentos}

Para a obtenção dos dados, utilizaram-se entrevistas, contagem de pedestres, contagem classificada volumétrica de veículos e/ou dados de controle eletrônico, quando disponíveis. Na Tabela 2 são caracterizados: as formas de obtenção de dados para cada categoria de empreendimento investigada neste estudo, o período de obtenção e o tamanho da amostra, quando utilizadas entrevistas. Para as entrevistas, foram desenvolvidos questionários com os campos: escolha modal para chegada e saída do empreendimento, motivo de ida ao empreendimento (funcionário, visitante, fornecedor, paciente, aluno, etc.), local onde estacionou o veículo para aqueles que utilizaram automóvel ou motocicleta, turno de trabalho ou estudo.

Quando os dados foram obtidos por meio de contagem classificada volumétrica de veículos e da contagem de pedestres, monitorou-se todas as entradas e saídas dos empreendimentos durante o período de coleta. Os dados de catraca foram disponibilizados pelos gestores dos empreendimentos. Os dados foram coletados em um número mínimo de cinco empreendimentos por categoria analisada, observando características de similaridade entre os mesmos e, ainda, considerando as características dos empreendimentos mais licenciados pela Prefeitura de Belo Horizonte. Os empreendimentos selecionados foram analisados anteriormente pela BHTRANS para verificação do impacto viário dentro de um processo de licenciamento ambiental ou urbanístico. Na Figura 2 são apresentadas as localizações dos estabelecimentos. Os demais dados, relativos à edificação, foram obtidos diretamente dos projetos de licenciamento e confirmados por meio de novas visitas e contato telefônico com os responsáveis pelos empreendimentos. 
Tabela 2: Caracterização dos dados coletados por categoria

\begin{tabular}{|c|c|c|c|}
\hline Categoria & $\begin{array}{l}\text { Forma de obtenção de } \\
\text { dados }\end{array}$ & $\begin{array}{l}\text { Período de obtenção } \\
\text { dos dados }\end{array}$ & Amostra \\
\hline Casas Noturnas & $\begin{array}{l}\text { Entrevista } \\
\text { Contagem de Pedestre }\end{array}$ & $\begin{array}{l}\text { Quinta a sábado } \\
20 \mathrm{~h}-02 \mathrm{~h}\end{array}$ & $\begin{array}{l}680 \text { entrevistas em } 8 \\
\text { estabelecimentos e contagem } \\
\text { em } 5 \text { estabelecimentos }\end{array}$ \\
\hline $\begin{array}{l}\text { Condomínios } \\
\text { residenciais }\end{array}$ & $\begin{array}{l}\text { Contagem classificada } \\
\text { volumétrica }\end{array}$ & $\begin{array}{l}\text { Segunda-feira a } \\
\text { quinta-feira } \\
\text { 06h-19h }\end{array}$ & $\begin{array}{l}\text { Contagem volumétrica em } 5 \\
\text { estabelecimentos }\end{array}$ \\
\hline $\begin{array}{l}\text { Escolas de Ensino } \\
\text { Fundamental e } \\
\text { Médio }\end{array}$ & Entrevista & Coletada pela escola & $\begin{array}{l}10.088 \text { entrevistas em } 5 \\
\text { estabelecimentos privados }\end{array}$ \\
\hline Hospitais & $\begin{array}{l}\text { Entrevistas } \\
\text { Contagem de Pedestres }\end{array}$ & $06 h-11 h$ & $\begin{array}{l}\text { Contagem e entrevista em } 5 \\
\text { estabelecimentos }\end{array}$ \\
\hline Shopping center & Dados de catraca & $\begin{array}{l}\text { Domingo a sábado } \\
6-23 \mathrm{~h}\end{array}$ & $\begin{array}{l}\text { Dados de catraca de } 5 \\
\text { estabelecimentos }\end{array}$ \\
\hline Supermercados & Dados de catraca & $\begin{array}{l}\text { Segunda-feira a } \\
\text { sexta-feira } 6 h-20 h\end{array}$ & $\begin{array}{l}\text { Dados de catraca de } 5 \\
\text { estabelecimentos }\end{array}$ \\
\hline Universidades & Entrevistas & $\begin{array}{l}\text { Manhã e noite durante } \\
\text { período letivo }\end{array}$ & $\begin{array}{l}7.693 \text { usuários em } 5 \\
\text { estabelecimentos privados }\end{array}$ \\
\hline
\end{tabular}

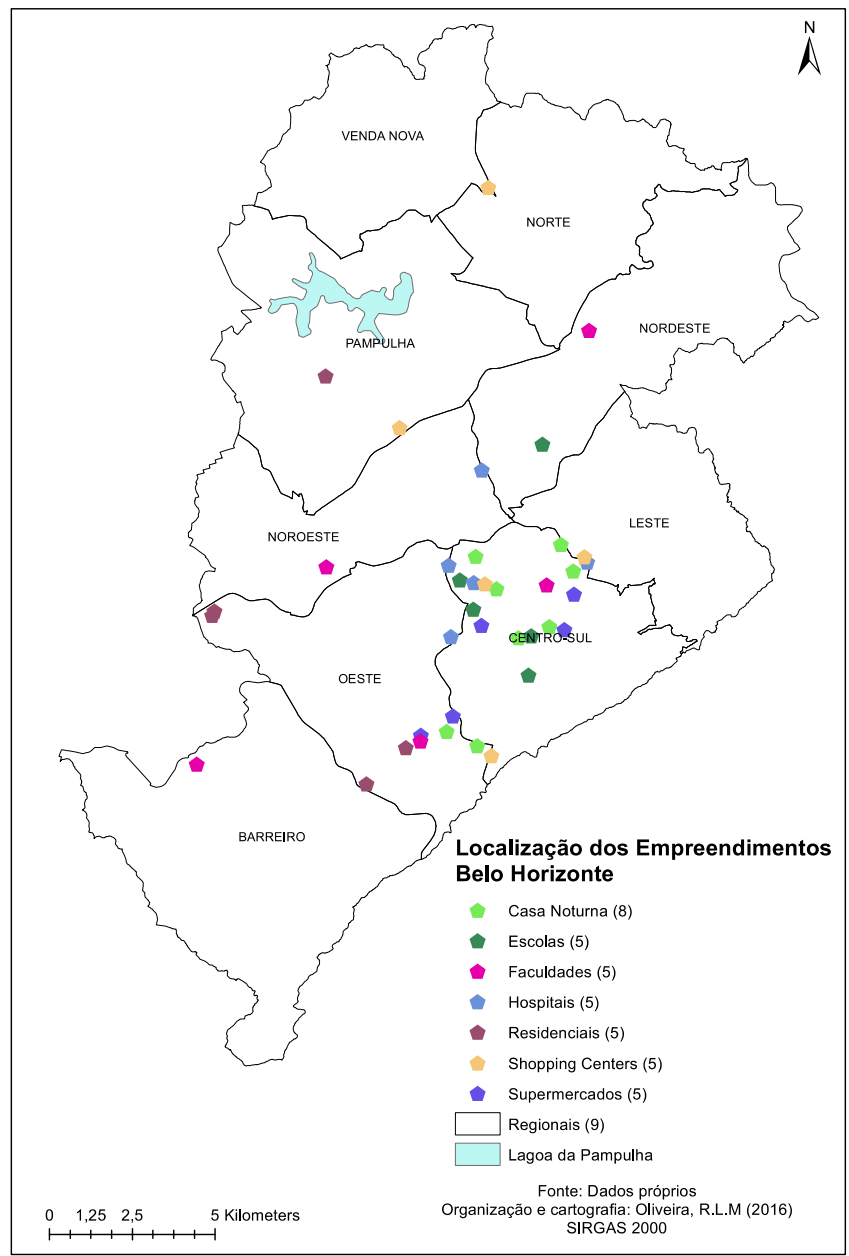

Figura 2. Localização dos Estabelecimentos Pesquisados para Belo Horizonte 
Na Figura 3 é apresentada a divisão modal para casas noturnas, escolas, hospitais e IESs. 0 automóvel é o modo predominante para viagens com destino a casas noturnas e escolas e o transporte público é o mais utilizado por usuários de hospitais e IESs. Em condomínios residenciais, shopping centers e supermercados, analisou-se apenas as viagens de automóveis, considerando que se deseja determinar as viagens atraídas e/ou produzidas por este tipo de veículo.

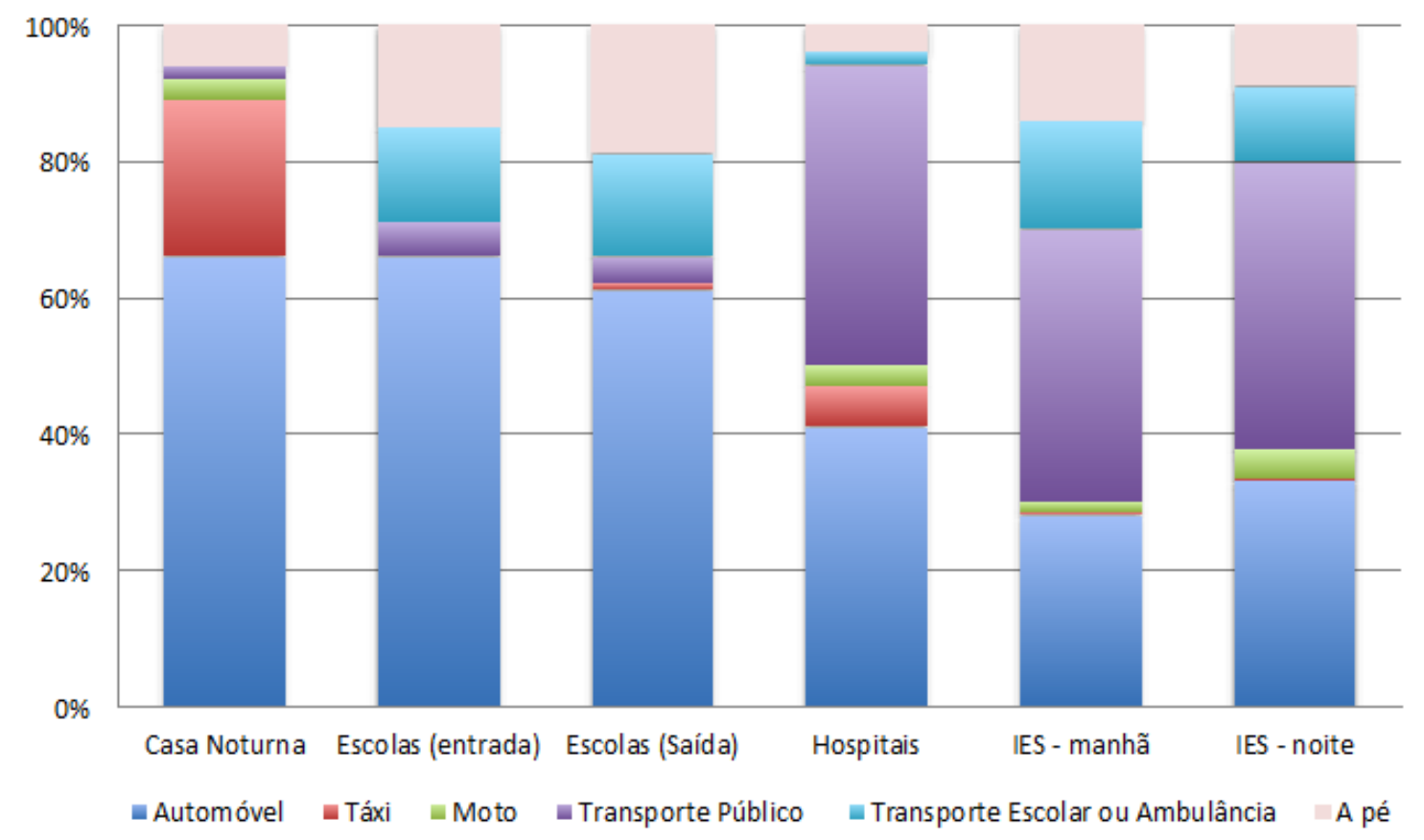

Figura 3. Divisão modal

Na Tabela 3 são apresentadas as principais características dos empreendimentos que compuseram a amostra, a hora-pico de atração de viagens e o percentual de viagens atraídas.

\subsection{Definição das variáveis}

Inicialmente, conduziu-se uma análise das variáveis consideradas para cada empreendimento por meio de estatística descritiva, visando tecer uma análise preliminar da estrutura e da variabilidade dos dados coletados entre os empreendimentos para cada categoria. Na Tabela 4 são apresentadas as variáveis utilizadas neste desenvolvimento, com os valores mínimos, máximo, média e desvio padrão, além da correlação estatística entre a variável dependente e as variáveis independentes.

Os resultados da análise de correlação entre a variável dependente e as variáveis independentes, utilizando o coeficiente de correlação de Pearson indicam que as categorias condomínio residencial e supermercado apresentam baixa correlação para estas variáveis. Ressalta-se, ainda, que a correlação foi negativa para hospitais (área construída) e supermercados (checkout).

A correlação entre as variáveis analisadas para os condomínios residenciais, apesar de não se caracterizar por um valor elevado, é válida. Optou-se por desenvolver os modelos a fim de compará-los com os existentes, pois as variáveis são similares àquelas utilizadas na literatura para desenvolvimento de modelos de geração de viagens. Dessa maneira, possibilita-se compa- 
ração entre os modelos, apesar da necessidade de um estudo mais detalhado sobre esta categoria de PGV.

Tabela 3: Horário de Pico e percentual de atração e produção de viagens nos empreendimentos analisados

\begin{tabular}{|c|c|c|c|c|}
\hline \multicolumn{2}{|l|}{ Empreendimento } & \multicolumn{3}{|c|}{ Viagens Atraídas } \\
\hline Categoria & Características & ID & Hora-Pico & Percentual \\
\hline \multirow{5}{*}{ Casa Noturna (CN) } & \multirow{5}{*}{ Empreendimentos com música ao vivo } & CN1 & $23: 30-00: 30$ & $92 \%$ \\
\hline & & CN2 & $23: 30-00: 30$ & $97 \%$ \\
\hline & & CN3 & $22: 30-23: 30$ & $100 \%$ \\
\hline & & CN4 & $23: 30-00: 30$ & $100 \%$ \\
\hline & & CN5 & $23: 30-00: 30$ & $100 \%$ \\
\hline \multirow{10}{*}{$\begin{array}{l}\text { Condomínio } \\
\text { residencial (CR) }\end{array}$} & \multirow{10}{*}{$\begin{array}{l}\text { Edifícios com apartamentos de } 2 / 3 \text { quartos, } \\
\text { destinados às faixas de renda com padrão } \\
\text { médio-baixo e no mínimo uma vaga de } \\
\text { estacionamento por apartamento }\end{array}$} & CR 1 & $07: 00-08: 00^{i}$ & $89 \%$ \\
\hline & & & 18:00-19:00 & $41 \%$ \\
\hline & & CR 2 & 07:00-08:00 & $76 \%$ \\
\hline & & & 18:00-19:00 & $33 \%$ \\
\hline & & CR 3 & 07:00-08:00 & $96 \%$ \\
\hline & & & 18:00-19:00 & $29 \%$ \\
\hline & & CR 4 & 07:00-08:00 & $78 \%$ \\
\hline & & & 18:00-19:00 & $25 \%$ \\
\hline & & CR 5 & 07:00-08:00 & $91 \%$ \\
\hline & & & 18:00-19:00 & $25 \%$ \\
\hline \multirow{5}{*}{$\begin{array}{l}\text { Estabelecimento de } \\
\text { Ensino Fundamental } \\
\text { (EF) }\end{array}$} & \multirow{5}{*}{$\begin{array}{l}\text { As escolas de ensino fundamental e médio } \\
\text { são, exclusivamente, instituições privadas e } \\
\text { com oferta simultânea dos dois níveis de } \\
\text { ensino }\end{array}$} & EF 1 & & $57 \%^{\mathrm{ii}}$ \\
\hline & & $\mathrm{EF} 2$ & & $70 \%$ \\
\hline & & EF 3 & Dia útil & $73 \%$ \\
\hline & & EF 4 & & $62 \%$ \\
\hline & & EF 5 & & $73 \%$ \\
\hline \multirow{5}{*}{ Hospital (HO) } & \multirow{5}{*}{$\begin{array}{l}\text { Instituições privadas com oferta de serviço } \\
\text { de pronto-socorro }\end{array}$} & $\mathrm{HO} 1$ & 07:00-08:00 & $38 \%$ \\
\hline & & $\mathrm{HO} 2$ & 07:00-08:00 & $34 \%$ \\
\hline & & $\mathrm{HO} 3$ & 08:00-09:00 & $34 \%$ \\
\hline & & $\mathrm{HO} 4$ & 08:00-09:00 & $57 \%$ \\
\hline & & $\mathrm{HO} 5$ & 08:00-09:00 & $39 \%$ \\
\hline \multirow{10}{*}{$\begin{array}{l}\text { Instituição de Ensino } \\
\text { Superior (IES) }\end{array}$} & \multirow{10}{*}{ Instituições de ensino superior privadas } & IES 1 & 08:00-09:00 & $68 \%$ \\
\hline & & & 19:00-20:00 & $47 \%$ \\
\hline & & IES 2 & 08:00-09:00 & $96 \%$ \\
\hline & & & 19:00-20:00 & $71 \%$ \\
\hline & & IES 3 & 08:00-09:00 & $32 \%$ \\
\hline & & & 19:00-20:00 & $51 \%$ \\
\hline & & IES 4 & 08:00-09:00 & $28 \%$ \\
\hline & & & 19:00-20:00 & $58 \%$ \\
\hline & & IES 5 & 08:00-09:00 & $25 \%$ \\
\hline & & & 19:00-20:00 & $55 \%$ \\
\hline \multirow{5}{*}{$\begin{array}{l}\text { Shopping Center } \\
\text { (SC) }\end{array}$} & \multirow{5}{*}{$\begin{array}{l}\text { Empreendimentos com múltiplas lojas e } \\
\text { estacionamento amplo e controlado, com a } \\
\text { presença de supermercados }\end{array}$} & SC 1 & $18: 00-19: 00^{\mathrm{iii}}$ & $50 \%$ \\
\hline & & SC 2 & 18:00-19:00 & $59 \%$ \\
\hline & & SC 3 & 18:00-19:00 & $51 \%$ \\
\hline & & SC 4 & 18:00-19:00 & $52 \%$ \\
\hline & & SC 5 & $18: 00-19: 00$ & $56 \%$ \\
\hline \multirow{5}{*}{ Supermercado (SU) } & \multirow{5}{*}{$\begin{array}{l}\text { Estabelecimentos com estacionamento com } \\
\text { controle de acesso (catraca) }\end{array}$} & SU 1 & 19:00-20:00 iv & $47 \%$ \\
\hline & & SU 2 & 19:00-20:00 & $51 \%$ \\
\hline & & SU 3 & 19:00-20:00 & $51 \%$ \\
\hline & & SU 4 & 19:00-20:00 & $76 \%$ \\
\hline & & SU 5 & 19:00-20:00 & $58 \%$ \\
\hline
\end{tabular}

Em condomínio residencial, considerou-se a atração de viagens no início e final do dia, em uma terça-feira.

Percentual em relação ao período da manhã.

O fluxo permanece constante entre $15 \mathrm{~h}$ e $20 \mathrm{~h}$, próximo de 1.200 veículo/hora com mesma proporcionalidade média de viagens atraídas entre 17 $19 \mathrm{~h}$, de $50 \%$.

Viagens atraídas por veículos particulares em uma sexta-feira. 
Tabela 4: Principais informações das variáveis independentes e teste de correlação das variáveis

\begin{tabular}{|c|c|c|c|c|c|c|c|}
\hline \multirow[b]{2}{*}{ Categoria } & \multirow[b]{2}{*}{ Variáveis Independente } & \multicolumn{4}{|c|}{ Valores } & \multirow[b]{2}{*}{$\begin{array}{l}\text { Variável } \\
\text { Dependente }\end{array}$} & \multirow[b]{2}{*}{ Correlação (Pearson) } \\
\hline & & Mínimo & Máximo & Médio & $\begin{array}{l}\text { Desvio } \\
\text { Padrão }\end{array}$ & & \\
\hline \multirow[b]{2}{*}{ Casas Noturnas } & Área Construída $\left(\mathrm{m}^{2}\right)$ & 386 & 1.722 & 1.056 & 479 & \multirow[b]{2}{*}{ Viagens Atraídas } & 0,88 (atração) \\
\hline & $\begin{array}{l}\text { Capacidade do } \\
\text { Estabelecimento }\end{array}$ & 380 & 900 & 622 & 180 & & 0,96 (atração) \\
\hline \multirow{3}{*}{$\begin{array}{l}\text { Condomínios } \\
\text { Residenciais }\end{array}$} & Número de Quartos & 268 & 460 & 384 & 73 & \multirow{3}{*}{ Viagens Geradas ${ }^{v}$} & $\begin{array}{c}\text { 0,29 (atração) e 0,36 } \\
\text { (produção) }\end{array}$ \\
\hline & $\begin{array}{l}\text { Número de Unidades } \\
\text { Residenciais }\end{array}$ & 120 & 184 & 153 & 24 & & $\begin{array}{c}\text { 0,62 (atração) e 0,65 } \\
\text { (produção) }\end{array}$ \\
\hline & Área Construída $\left(\mathrm{m}^{2}\right)$ & 5.875 & 19.366 & 12.084 & 5.038 & & $\begin{array}{c}\text { 0,35 (atração) e 0,42 } \\
\text { (produção) }\end{array}$ \\
\hline \multirow{4}{*}{$\begin{array}{l}\text { Estabelecimentos } \\
\text { de Ensino } \\
\text { Fundamental }\end{array}$} & Área Construída $\left(\mathrm{m}^{2}\right)$ & 2.530 & 36.000 & 18.195 & 11.235 & \multirow{4}{*}{ Viagens Atraídas } & 0,57 (atração) \\
\hline & Número de Salas & 16 & 80 & 55 & 22 & & 0,73 (atração) \\
\hline & Número de Alunos & 841 & 2.943 & 2.264 & 766 & & 0,81 (atração) \\
\hline & Número de Funcionários & 131 & 390 & 293 & 88 & & 0,93 (atração) \\
\hline \multirow{3}{*}{ Hospitais } & Número de Leitos & 141 & 320 & 272 & 67 & \multirow{3}{*}{ Viagens Atraídas } & 0,35 (atração) \\
\hline & Número de Funcionários & 761 & 1.966 & 1.367 & 435 & & 0,65 (atração) \\
\hline & Área Construída $\left(\mathrm{m}^{2}\right)$ & 23.906 & 33.725 & 30.188 & 3.570 & & $-0,13$ (atração) \\
\hline \multirow{3}{*}{$\begin{array}{l}\text { Institutos de } \\
\text { Ensino Superior }\end{array}$} & Área Construída $\left(\mathrm{m}^{2}\right)$ & 6.725 & 74.280 & 35.826 & 25.548 & \multirow{3}{*}{ Viagens Atraídas } & $\begin{array}{c}0,96 \text { (manhã) e } 0,85 \\
\text { (noite) }\end{array}$ \\
\hline & Número de Salas & 41 & 201 & 116 & 56 & & $\begin{array}{c}0,95 \text { (manhã) e } 0,85 \\
\text { (noite) }\end{array}$ \\
\hline & $\begin{array}{l}\text { Número de Vagas de } \\
\text { Estacionamento }\end{array}$ & 190 & 2.195 & 1.068 & 662 & & $\begin{array}{c}0,98 \text { (manhã) e } 0,88 \\
\text { (noite) }\end{array}$ \\
\hline \multirow{4}{*}{ Shopping Center } & Área Construída $\left(\mathrm{m}^{2}\right)$ & 82.131 & 182.681 & 151.890 & 36.389 & \multirow{4}{*}{ Viagens Geradas } & 0,48 (atração) \\
\hline & $\begin{array}{l}\text { Número de Vagas de } \\
\text { Estacionamento }\end{array}$ & 1.268 & 3.710 & 2.286 & 806 & & 0,95 (atração) \\
\hline & Número de Lojas & 179 & 300 & 232 & 43 & & 0,58 (atração) \\
\hline & $\begin{array}{l}\text { Capacidade da Sala do } \\
\text { Cinema }\end{array}$ & 1.010 & 2.037 & 1.366 & 370 & & 0,85 (atração) \\
\hline \multirow{3}{*}{ Supermercado } & Área construída $\left(\mathrm{m}^{2}\right)$ & 5.965 & 10.016 & 7.957 & 1.425 & \multirow{3}{*}{ Viagens Geradas } & 0,37 (atração) \\
\hline & $\begin{array}{l}\text { Número de Vagas de } \\
\text { Estacionamento }\end{array}$ & 70 & 173 & 106 & 36 & & 0,39 (atração) \\
\hline & Número de Checkout & 12 & 19 & 15 & 2 & & $-0,71$ (atração) \\
\hline
\end{tabular}

A atração de viagens acontece na hora-pico da noite (18:00-19:00) e a produção de viagens, na hora-pico da manhã (07:00-08:00), conforme tabela 4.

\section{RESULTADOS}

Neste estudo foram desenvolvidos modelos utilizando como técnica a regressão linear, bem como realizados testes dos modelos utilizando regressão linear múltipla, combinando as diferentes variáveis independentes. Na Tabela 5 são apresentados os modelos para as sete diferentes categorias de empreendimentos em Belo Horizonte. Para cada modelo são apresentados os testes estatísticos ( $\mathrm{R}^{2}$, teste-t e p-valor) e a raiz do erro quadrático médio (REQM) para validação do modelo mais adequado. Os modelos válidos estão destacados em negrito. Os modelos foram gerados utilizando o software StatPlus Pro, versão 6 (http://www.analystsoft.com/br/) e para validação implementou-se scripts no software $R$.

Os resultados indicam que os modelos apresentados possuem acurácia estatística, exceto para os modelos de produção de viagens em condomínios residenciais. A validação cruzada (LOOCV) indicou os melhores modelos para geração de viagem por categoria, destacados em negrito na Tabela 5. É importante destacar que, além da validação dos modelos, foi observada a relação nexo causal entre as variáveis independentes e a variável dependente. Em alguns modelos com bom desempenho explanatório sob a ótica estatística, identificou-se problemas quanto à relação de causa e efeito, invalidando sua pertinência e, consequente, aplicação. Estes modelos não foram apresentados neste trabalho. 
Tabela 5: Modelos de Geração de Viagens para Belo Horizonte

\begin{tabular}{|c|c|c|c|c|c|c|}
\hline Categoria & $\begin{array}{l}\text { Tipo de Modelo } \\
\text { e Dimensão } \\
\text { Temporal }\end{array}$ & Equação & $\mathbf{R}^{2}$ & $\begin{array}{l}\text { Teste- } \\
\text { tei }^{\text {vi }}(5 \%)\end{array}$ & p-valorvii & $\begin{array}{c}\text { Leave-one-out } \\
\text { Cross-Validation } \\
\text { (REMQ) }\end{array}$ \\
\hline \multirow{3}{*}{ Casa Noturna } & \multirow{3}{*}{$\begin{array}{c}\text { Atração } \\
\text { 23:30-00:30h }\end{array}$} & V = 0,43 Capacidade $-161,86$ & 0,91 & $\begin{array}{l}5,62 \\
-3,24\end{array}$ & $\begin{array}{l}0,01 \\
0,04\end{array}$ & 48,30 \\
\hline & & \multirow[b]{2}{*}{$V=0,15$ Área Construída - 50,60 } & \multirow[b]{2}{*}{0,77} & 3,22 & 0,04 & \multirow{2}{*}{72,45} \\
\hline & & & & $-0,93$ & 0,41 & \\
\hline Condomínio & Geração & $V=0,28$ Quartos & 0,40 & 1,63 & 0,17 & 261,08 \\
\hline Residencial & 8:00-9:00 & $\mathrm{V}=0,74$ Unidade Residencial & 0,44 & 1,77 & 0,15 & 189,23 \\
\hline \multirow{4}{*}{$\begin{array}{l}\text { Escola de Ensino } \\
\text { Fundamental e } \\
\text { Médio }\end{array}$} & \multirow{4}{*}{$\begin{array}{c}\text { Atração } \\
7-8 \mathrm{~h}\end{array}$} & $V=0,0517$ Construída & 0,80 & 4,03 & 0,01 & 948,37 \\
\hline & & $V=19,66$ Salas & 0,91 & 6,29 & 0,03 & $1.014,76$ \\
\hline & & $V=0,50$ Alunos & 0,92 & 7,25 & 0,002 & $1.364,70$ \\
\hline & & V = 3,95 Funcionários & 0,95 & 9,22 & 0,0007 & 750,61 \\
\hline \multirow{3}{*}{ Hospital } & \multirow{3}{*}{$\begin{array}{l}\text { Atração } \\
8-9 h\end{array}$} & V = 0,006 Área Construída & 0,77 & 3,69 & 0,02 & $1.909,91$ \\
\hline & & $\mathrm{V}=0,1$ Funcionários & 0,88 & 5,40 & 0,005 & $3.092,29$ \\
\hline & & $V=0,54$ Leitos & 0,82 & 4,22 & 0,01 & $12.445,62$ \\
\hline \multirow{10}{*}{$\begin{array}{l}\text { Instituição de } \\
\text { Ensino Superior }\end{array}$} & \multirow{10}{*}{$\begin{array}{l}\text { Atração } \\
\text { Manhã }\end{array}$} & \multirow{2}{*}{$V_{\text {alunos }}=0,054$ ÁreaConstruída +857} & \multirow{2}{*}{0,91} & 5,69 & 0,01 & \multirow{2}{*}{800,04} \\
\hline & & & & 2,04 & 0,13 & \\
\hline & & \multirow{2}{*}{ 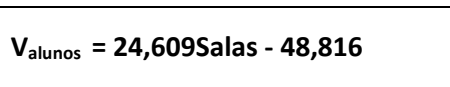 } & \multirow{2}{*}{0,91} & 5,47 & 0,012 & \multirow{2}{*}{853,98} \\
\hline & & & & $-0,08$ & 0,938 & \\
\hline & & \multirow{2}{*}{$V_{\text {alunos }}=2,1486$ Vagas $+515,6432$} & \multirow{2}{*}{0,96} & 8,056 & 0,004 & \multirow{2}{*}{753,70} \\
\hline & & & & 1,538 & 0,222 & \\
\hline & & $V_{\text {alunos }}=3,8274$ Funcionários + & & 11,286 & 0,00776 & \\
\hline & & 1192,9589 & 0,98 & 6,163 & 0,02533 & 7447,14 \\
\hline & & \multirow{2}{*}{$V_{\text {alunos }}=153,693$ Cursos $+190,994$} & \multirow{2}{*}{0,99} & 15,734 & 0,00402 & \multirow{2}{*}{$3.278,25$} \\
\hline & & & & 1,013 & 0,41752 & \\
\hline \multirow{4}{*}{ Shopping Center } & \multirow{4}{*}{$\begin{array}{c}\text { Geração } \\
\text { 18:00-19:00 }\end{array}$} & $V=0,0089$ Área Construída & 0,91 & 6,34 & 0,03 & $3.022,29$ \\
\hline & & V = 0,60 Número Vagas & 0,98 & 18,50 & 0,00 & 452,44 \\
\hline & & $V=10,25$ Número Lojas & 0,94 & 12,44 & 0,00 & 809,72 \\
\hline & & V = 1,02 Capacidade Cinema & 0,96 & 11,09 & 0,00 & 862,80 \\
\hline \multirow{3}{*}{ Supermercado } & \multirow{3}{*}{$\begin{array}{l}\text { Atração } \\
19-20\end{array}$} & V = 0,062 Área Construída & 0,81 & 4,13 & 0,02 & 462,37 \\
\hline & & $V=4,41$ Número Vagas & 0,80 & 3,99 & 0,02 & 896,25 \\
\hline & & $V=30,1$ Check-out & 0,68 & 2,90 & 0,04 & 513,2746 \\
\hline
\end{tabular}

Os valores estão apresentados na mesma sequência dos termos da equação. Nível de significância de $5 \%$.

Os valores estão apresentados na mesma sequência dos termos da equação.

\subsection{Comparação com os modelos nacionais}

Na Figura 4 é apresentada a comparação dos modelos desenvolvidos neste estudo com aqueles presentes na literatura nacional. Para tanto, utilizaram-se os dados reais referentes aos empreendimentos para determinação do número de viagens por meio do modelo mais ajustado gerado a partir deste trabalho e por meio dos modelos presentes na literatura. Esta análise não foi desenvolvida para casas noturnas, uma vez que não existe um modelo nacional para a categoria.

Atualmente, para Belo Horizonte, sugere-se a utilização dos modelos da literatura nacional para estimativa da geração de viagens na análise do impacto de novos empreendimentos na cidade. Apesar de nem sempre correlacionar as mesmas variáveis, a comparação entre os modelos, por meio da comparação da geração de viagens, indicou ser mais adequada a utilização dos modelos apresentados neste artigo, visto que contemplam as características locais sendo, portanto, melhores para a predição da geração de viagem nesta cidade.

Para condomínios residenciais, apesar de não ter sido validado estatisticamente, de forma comparativa os resultados são bem inferiores quando confrontados com aqueles obtidos por Grieco e Portugal (2010), gerando o número de viagens a partir do modelo apresentado por aqueles autores. 
Figura 4. Representação gráfica comparativa dos modelos de geração de viagens

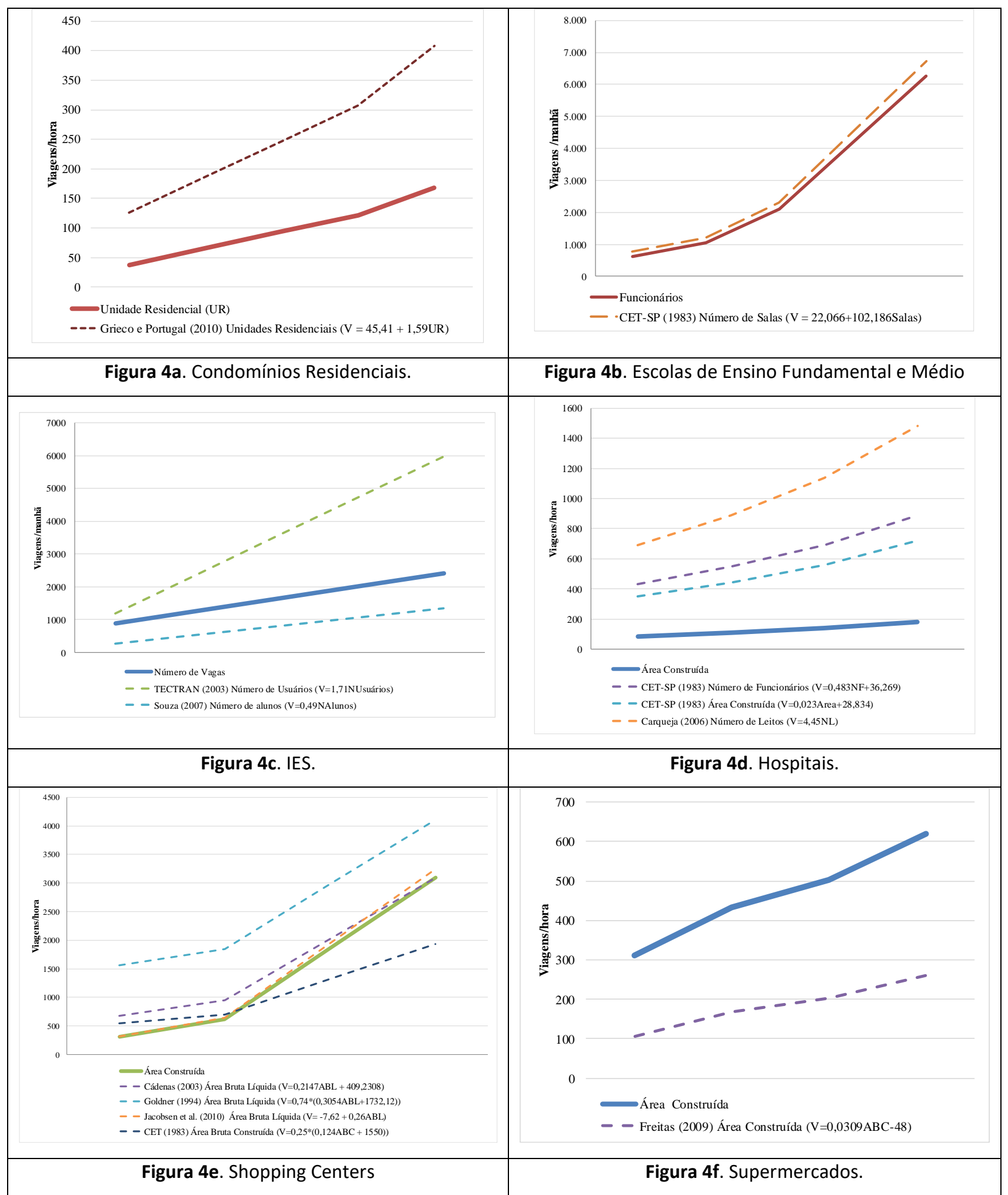

O modelo para escolas de ensino fundamental e médio, que considera o número de funcionários, apresentou comportamento similar ao modelo CET-SP (1983). Para hospitais, os três modelos apresentados possuem o mesmo comportamento dos dados, mas superestimam a geração de viagens. 0 modelo da literatura que mais se aproxima em relação ao nível do modelo gerado por meio deste trabalho (CET-SP, 1983) também considera a área construída como a variável explicativa. 
Para instituições de ensino superior, os modelos apresentaram grande divergência em relação ao nível, sendo que Tectran $(2003 a, b)$ superestima o número de viagens (este modelo foi desenvolvido para instituições de ensino público) e Souza (2007) subestima tal número. Assim, nesta categoria mostra-se a importância do desenvolvimento de modelos locais para análise da geração de viagens.

Para shopping centers, o modelo obtido neste trabalho gera um número inferior de viagens, quando comparados com Goldner (1994), Cádenas (2003), e CET-SP (1983) para área bruta construída de até $10.000 \mathrm{~m} 2$. Para áreas maiores, o modelo gerado apresenta a mesma tendência dos modelos de Goldner (1994), Jacobsen et al. (2010) e Cádenas (2003). Entretanto, em relação ao nível, o modelo de Jacobsen et al. (2010) é bastante similar ao desenvolvido neste trabalho. Além disso, o modelo de Goldner (1994) superestima o número de viagens para toda a amplitude de dados analisada para a variável explicativa. Ressalta-se que os modelos não foram comparados com CET-SP (2011) por não haver informações da área computável, sendo esta variável passível de discussão.

0 modelo para supermercados gera viagens bastante superiores quando comparado com Freitas (2009). Destaca-se que não houve comparação com outros modelos, devido à escassez de dados reais.

\subsection{Discussão dos Resultados}

Os modelos de geração de viagens são utilizados para identificar o impacto de novos empreendimentos no sistema viário para proposição de medidas mitigadoras, a serem adotadas pelo empreendedor visando a redução das externalidades a partir da implantação do novo empreendimento. Assim, modelos que reflitam a realidade da região analisada são importantes para reduzir o viés e a discussão acerca do impacto.

Neste estudo foram desenvolvidos modelos para geração de viagens para sete diferentes categorias de empreendimentos: casas noturnas, condomínios residenciais, escolas de ensino fundamental e médio, hospital, instituições de ensino superior, shopping center e supermercado.

Para casas noturnas, escolas de ensino fundamental e médio, hospitais, instituições de ensino superior, shopping centers e supermercados, os resultados foram satisfatórios, com validação do modelo que apresentou menor REQM a partir da validação cruzada pelo método leave-oneout e melhor ajuste. Sugere-se que nos próximos estudos a amostra de análise seja ampliada para criar diferentes categorias de empreendimentos e obter taxas mais precisas. Ainda, é interessante determinar modelos de geração de viagens para bares e restaurantes, que apresentam horário de pico e características de viagens diferentes das casas noturnas.

Em relação a condomínios, precisam ser identificadas outras variáveis de influência na geração de viagem. Para tanto, sugerem-se pesquisas com os moradores dos condomínios para entender os motivos das viagens realizadas por automóveis visando identificar possíveis relações com a geração de viagens e verificação da ocupação dos apartamentos.

Considerando as implicações práticas, os resultados aqui apresentados são úteis para o planejamento do transporte em Belo Horizonte. Até então, a utilização dos modelos de geração de viagens tem sido alvo de críticas, uma vez que os modelos não refletem as características e o comportamento de viagens em Belo Horizonte, visto que eram sugeridos modelos da literatura desenvolvidos para outras cidades.

Desta forma, apesar de existir discrepância e a necessidade de revisão dos modelos para 
algumas categorias, incrementando o número, o tipo de empreendimento e as variáveis independentes, os modelos podem auxiliar planejadores urbanos na análise dos impactos dos polos geradores de viagens na realidade belo-horizontina e na proposição de soluções mitigadoras/compensatórias.

Considerando as implicações científicas, este artigo apresentou modelos para casas noturnas, importante segmento em Belo Horizonte que carece de estudos. A metodologia para coleta de dados e as variáveis utilizadas mostram-se válidas, considerando a correlação entre os dados e os resultados obtidos. Por fim, a comparação entre os diversos modelos apresentados neste artigo com a literatura nacional evidencia a importância de modelos de geração de viagens locais, quando há necessidade de utilização destes para análise de impacto dos PGVs.

Importante destacar que alguns modelos, apesar de apresentarem boa correlação, tendem a determinar valores inferiores aos observados, conforme afirmado por Bertazzo et al. (2012). Desta forma, sugerem-se os modelos com melhor validação para uso nas análises de impacto viário em Belo Horizonte, a serem realizados pela Prefeitura de Belo Horizonte.

\section{CONSIDERAÇÕES FINAIS}

Neste artigo foram apresentados modelos de geração de viagens para sete categorias de empreendimentos: casas noturnas, condomínios residenciais, escolas de ensino fundamental e médio, hospitais, instituições de ensino superior, shopping centers e supermercados. 0 objetivo era verificar se os modelos desenvolvidos com dados de Belo Horizonte apresentam discrepância quando comparados com modelos nacionais, além de subsidiar futuros estudos de análises de impacto viário.

As variáveis utilizadas no estudo apresentaram correlação e os modelos foram validados estatisticamente, exceto para condomínios residenciais. 0 estudo apresentou modelos para casas noturnas, ainda não disponível na realidade ibérico-americana, cujos dados foram obtidos por meio de contagem de pedestres e entrevistas. Para shopping centers, a capacidade da sala do cinema mostrou-se como uma nova variável explicativa para geração de viagens de automóveis, apesar do modelo mais adequado considerar a área construída como variável explicativa.

Como resultado deste estudo, sugere-se a utilização dos modelos validados por meio do método de validação cruzada Leave-one-out com menor raiz do erro quadrático médio, mesmo que apresente melhor significância estatística, por gerarem valores mais próximos dos observados. Os resultados obtidos são importantes para o planejamento de transporte urbano de Belo Horizonte. Por fim, os modelos desenvolvidos especificamente para as viagens de empreendimentos localizados em Belo Horizonte podem ser utilizados de forma preditiva para estimar e avaliar o impacto da implementação de novos empreendimentos nesta cidade e, adicionalmente, subsidiar a proposição de medidas mitigadoras para redução das externalidades causadas pelo incremento de tráfego no sistema viário.

\section{AGRADECIMENTOS}

As autoras agradecem aos empreendimentos pesquisados pela disponibilidade de dados e em colaborar com a coleta de informações para o desenvolvimento deste estudo. Ainda, as autoras agradecem a equipe do projeto Empreender Pró-BH da BHTRANS pelas importantes discussões no desenvolvimento do projeto que resultou este artigo. Por fim, as autoras agradecem aos revisores pelas importantes contribuições.

\section{REFERÊNCIAS}

Andrade, E. P. ; Portugal. L. S. (2012a). Geração de viagens em PGVs. In: Portugal. L.S. Polos geradores de viagens orientados a qualidade de vida e ambiental: modelos e taxas de geração de viagens. Rio de Janeiro: Interciência. Cap. 4, p. 107-129. 
Andrade, P. A. e L. S. Portugal (2012b). Shopping Centers. In: Portugal. L.S. Polos geradores de viagens orientados a qualidade de vida e ambiental: modelos e taxas de geração de viagens. Rio de Janeiro: Interciência. Cap. 5, p. 137-164.

Barbosa, H. M. e R. C. Gonçalves (2000). Polo gerador de tráfego: um estudo em supermercados. In: CONGRESSO DE PESQUISA E ENSINO EM TRANSPORTES, 14., 2000. Anais... Gramado.

Belo Horizonte (2010). Lei n 9.959, de 20 de julho de 2010. Alterações na legislação urbanística municipal. Belo Horizonte: Prefeitura Municipal de Belo Horizonte,.

Bertazzo, A. B. S. (2008). Estimativa e avaliação do padrão de viagens geradas para instituições de ensino médio. Dissertação (Mestrado) - Universidade de Brasília, Brasília.

Bertazzo, A. B. S., M. A. P. Jacques, J. Galarraga e M. Herz (2014). Análise da evolução das taxas de geração de viagens publicadas pelo ITE para estabelecimentos de ensino. Journal of Transport Literature, v. 8, n. 3, p. 139-171. DOI: 10.1590/S2238-10312014000300007.

Bertazzo, A. B. S., J. Galarraga, M. Herz e Jacques, M. A. P. (2012). Estabelecimentos de Ensino. In: Portugal. L.S. Polos geradores de viagens orientados a qualidade de vida e ambiental: modelos e taxas de geração de viagens. Rio de Janeiro: Interciência. Cap. 10, p. 287-328.

Brasil (2009). Código de trânsito brasileiro. Brasília: Senado Federal,

Cádenas, C. B. B. (2003). Geração de viagens e demanda por estacionamento em shopping centers no interior do Estado de São Paulo. Tese (Doutorado) - Universidade de São Paulo, São Carlos.

Carqueja, H. L. (2006). Estudo da geração de viagens e de parâmetros para o dimensionamento de estacionamento e meio-fio para Hospitais na grande Florianópolis. Trabalho de Conclusão de Curso (Graduação) - Universidade Federal de Santa Catarina, Florianópolis.

Castro, A. (2010). Polos geradores de tráfego: aplicação e impactos nos empreendimentos residenciais em São Paulo. Dissertação (Mestrado) - Universidade Presbiteriana Mackenzie, São Paulo.

CET-SP Companhia de Engenharia de Tráfego (1983). Polos geradores de tráfego. Boletim Técnico n⿳o 32. São Paulo: Prefeitura de São Paulo.

CET-SP Companhia de Engenharia de Tráfego (2000). Polos geradores de tráfego II. Boletim Técnico no ${ }^{36}$. São Paulo: Prefeitura de São Paulo.

CET- SP Companhia de Engenharia de Tráfego (2011). Modelos de atração de automóveis por shopping center. Boletim Técnico $n^{\circ}$ 46. São Paulo: Prefeitura de São Paulo.

Clifton, K. J., C. D. Muhs e K. M. Currans (2015). Adjusting ITE’s Trip Generation Handbook for urban context. The Journal of Transport and Land Use, v. 8, n. 1, p. 5-29. DOI: 10.5198/jtlu.2015.378

Denatran (2001). Manual de procedimentos para o tratamento de polos geradores de tráfego. Brasília: Denatran/FGV.

Ferreira, P. R. (2013). Geração de viagens em condomínios residenciais multifamiliares de classe média na Região Metropolitana da Grande Vitória. Dissertação (Mestrado) - Universidade Federal do Espírito Santo, Vitória.

Freitas, G. V. (2009). Metodologia de delimitação de área de influência e elaboração de modelo de geração de viagens para supermercados de cidades de médio porte. Dissertação (Mestrado) - Universidade Federal de São Carlos, São Carlos.

Galarraga, J. M. Herz, A. A. Raia Junior e G. V. Freitas (2012). Hipermercados e Supermercados. In: Portugal. L.S. Polos geradores de viagens orientados a qualidade de vida e ambiental: modelos e taxas de geração de viagens. Rio de Janeiro: Interciência. Cap. 12, p. 373-420.

Goldner, L. A. (1994). Uma metodologia de impacto de shopping centers sobre o sistema viário urbano. Tese (Doutorado)Universidade Federal do Rio de Janeiro, Rio de Janeiro.

Gonçalves, F. S., D. S. C. P. S. Lemos, E. C. Kneib, L. S. Portugal (2012) Caracterização dos Polos Geradores de Viagens. In: Portugal. L.S. Polos geradores de viagens orientados a qualidade de vida e ambiental: modelos e taxas de geração de viagens. Rio de Janeiro: Interciência. Cap. 1, p. 5-43.

Gontijo, G. A. S. (2014). Modelos e taxas de atração de viagens para pgvs-hospitais públicos localizados em cidades de médio porte do interior do Estado de São Paulo. Tese (Doutorado) - Universidade Federal de São Carlos, São Carlos.

Grando, L. (1986). A interferência dos polos geradores de tráfego no sistema viário: análise e contribuição metodológica para shopping centers. Dissertação (Mestrado) - Universidade Federal do Rio de Janeiro, Rio de Janeiro.

Grieco, E. P. e L. S. Portugal (2010). Taxas de geração de viagens em condomínios residenciais: estudo de caso. Transportes, v. 18, n. 1, p. 87-95. DOI: 10.14295/transportes.v18i1.386

Grieco, E., S. Marcolini, L. S. Portugal e O. Soares (2012). Estabelecimentos Residenciais. In: Portugal. L.S. Polos geradores de viagens orientados a qualidade de vida e ambiental: modelos e taxas de geração de viagens. Rio de Janeiro: Interciência. Cap. 7, p. 207-236

ITE (2008). Trip generation handbook, an ite recommended practice. Washington: Institute of Transportation Engineers,

Jacobsen, A. C., H. B. B. Cybis, L. A. Lindau, A. B. Pinto (2010). Modelos de geração e variabilidade no volume diário de veículos em shopping centers. Transportes, v. 18, n. 1, p. 105-113. DOI: 10.14295/transportes.v18i1.388

Kneib, E. C. (2004). Caracterização de empreendimentos geradores de viagens: contribuição conceitual à análise de seus impactos no uso, ocupação e valorização do solo urbano. Tese (Doutorado) - Universidade de Brasília, Brasília.

Macêdo, M. M., I. M. Filizola e E. A Souza (2002). Polos geradores de tráfego: estudo de um agrupamento de clínicas médicas. In: CONGRESSO DE PESQUISA E ENSINO EM TRANSPORTES, 16., 2002. Anais... Natal: ANPET.

Marcolini, S. (2011). Ambiente urbano e geração de viagens: Niterói, um estudo de caso. Dissertação (Mestrado) - Universidade Federal do Rio de Janeiro, Rio de Janeiro. 
Nishimori, F. T. I. e A. A. Raia Junior, A. A. (2011). Modelos de geração de viagens a prontos-socorros públicos. In: CONGRESSO DE PESQUISA E ENSINO EM TRANSPORTES, 25., 2011. Anais... Belo Horizonte: ANPET.

Nunes, J. L. (2005). Estudo da demanda por estacionamento em instituições de ensino superior. Dissertação (Mestrado) Universidade de Brasília, Brasília.

Pinto, C. R. S., L. S. Pires, L. S. Portugal e M. Rubert (2012). Megaeventos: impactos e estratégias de transporte. In: Portugal, L. S. Polos geradores de viagens orientados a qualidade de vida e ambiental: modelos e taxas de geração de Viagens. Rio de Janeiro: Interciência. Cap. 18, p. 599-635.

Portugal, L.S. e L. G. Goldner (2003). Estudo de pólos geradores de viagens e de seus impactos nos sistemas viários e de transportes. São Paulo, SP: Edgard Blücher.

Portugal, L. S. (2012). Polos geradores de viagens orientados a qualidade de vida e ambiental: modelos e taxas de geração de viagens. Rio de Janeiro: Interciência.

Rosa, T. F. A. (2003) Variáveis socioeconômicas na geração de viagens para shopping centers. Dissertação (Mestrado)- Instituto Militar de Engenharia, Rio de Janeiro.

Silva, A. N. R., M. O. Rodrigues e V. M. P. Pampolha (1995). Uma proposta para determinação do número de vagas para estacionamento em supermercados em função do nível de serviço desejável. In: CONGRESSO DE PESQUISA E ENSINO EM TRANSPORTES, 9., 1995. Anais... São Carlos, SP.

Silva, L. R. (2006). Metodologia de delimitação da área de influência dos pólos geradores de viagens para estudos de geração de viagens: um estudo de caso nos supermercados e hipermercados. Dissertação (Mestrado) - Universidade de Brasília, Brasília.

Souza, S. C. F. (2007). Modelos para estimativa de viagens geradas por instituições de ensino superior. Dissertação (Mestrado) Universidade de Brasília, Brasília.

TECTRAN (2003a). Relatório de impacto na circulação da escola de engenharia e da faculdade de ciências econômicas da Universidade Federal de Minas Gerais. Belo Horizonte: Técnicos em Transporte Ltda.,

TECTRAN (2003b). Estudo de circulação e estacionamento: unidade Arcos/PUC Minas. Belo Horizonte: Técnicos em Transporte.

Torquato, T. L. L. e A. A. Raia Júnior (2014). Modelos de geração de viagens para condomínios residenciais horizontais. Transportes, v. 22, n. 1, p.56-64. DOI: 10.14295/transportes.v22i1.708. 